\title{
Review \\ p21-activated kinase signaling in breast cancer
}

\section{Anupama E Gururaj, Suresh K Rayala and Rakesh Kumar}

\author{
Department of Molecular and Cellular Oncology, The University of Texas MD Anderson Cancer Center, Houston, Texas, USA \\ Corresponding author: Rakesh Kumar, rkumar@mdanderson.org \\ Published: 2 November 2004
}

Breast Cancer Res 2005, 7:5-12 (DOI 10.1186/bcr961)

(C) 2005 BioMed Central Ltd

\begin{abstract}
The p21-activated kinases signal through a number of cellular pathways fundamental to growth, differentiation and apoptosis. A wealth of information has accumulated at an impressive pace in the recent past, both with regard to previously identified targets for p21-activated kinases that regulate the actin cytoskeleton and cellular stress pathways and with regard to newly identified targets and their role in cancer. Emerging data also provide new clues towards a previously unappreciated link between these various cellular processes. The present review attempts to provide a quick tutorial to the reader about the evolving significance of p21-activated kinases and small GTPases in breast cancer, using information from mouse models, tissue culture studies, and human materials.
\end{abstract}

Keywords: breast cancer, hormone independence, mouse model, p21-activated kinase, Rho GTPase

\section{Introduction}

Tumor progression involves the transition of normal cells into malignant cells through a series of cumulative alterations. Invasive and migratory properties are acquired during this process, enabling cells to metastasize (travel to and grow in tissues far from their origin). Cell proliferation, cell motility, and cell survival are regulated by multiple factors, and the changes that occur in cancer cells are the result of multiple alterations in the cellular signaling machinery. Successful cell migration depends on the regulation of the timing of movement, the guidance of motile cells, and the cytoskeletal and adhesive characteristic changes within the cells.

The actin cytoskeleton is the primary determinant of cell shape and motility. The small Rho (p21) GTPases (Rho, Rac, and Cdc42) have been implicated in multiple steps during cellular transformation, including regulation of cytoskeletal reorganization and gene expression [1]. These p21s mediate growth factor-induced morphological changes that involve actin-based cellular structures. Rho mediates the formation of cytoskeletal stress fibers and focal adhesion, Rac mediates the formation of membrane ruffles and lamellipodia, and Cdc42 mediates the formation of peripheral filopodia and actin microspikes [1]. Many upstream regulators and downstream effectors of these small GTPases have been isolated, and their modes of activation and action have gradually been elucidated.

Mammalian kinases that bind to the GTP-bound forms of Rho p21s have been identified. These kinases include the evolutionarily conserved p21-activated serine/threonine kinase (PAK), which is stimulated by binding to Cdc42 and Rac, and the Rho-binding serine/threonine kinase. In the present review, we briefly summarize the progress made in understanding the PAK-family-induced biological function in breast cancer cells (Fig. 1). Comprehensive information on PAK family biology, signaling, and regulation is available in recent reviews [2-5].

\section{The PAK family}

Pak1, the first of the PAK family members to be discovered, was originally cloned from brain tissue as a p21-interacting kinase that was homologous to yeast Ste20 [6]. Subsequent identification of five other family members indicated that this family of protein kinases is

$\mathrm{DLC1}=$ dynein light chain 1; ER = estrogen receptor; HER = human epidermal growth factor receptor; MAPK = mitogen-activated protein kinase; $\mathrm{NF}=$ nuclear factor; PAK = p21-activated serine/threonine kinase; PI-3 = phosphatidylinositol $3 ;$ PKA $=$ protein kinase $A ;$ VEGF $=$ vascular endothelial growth factor. 


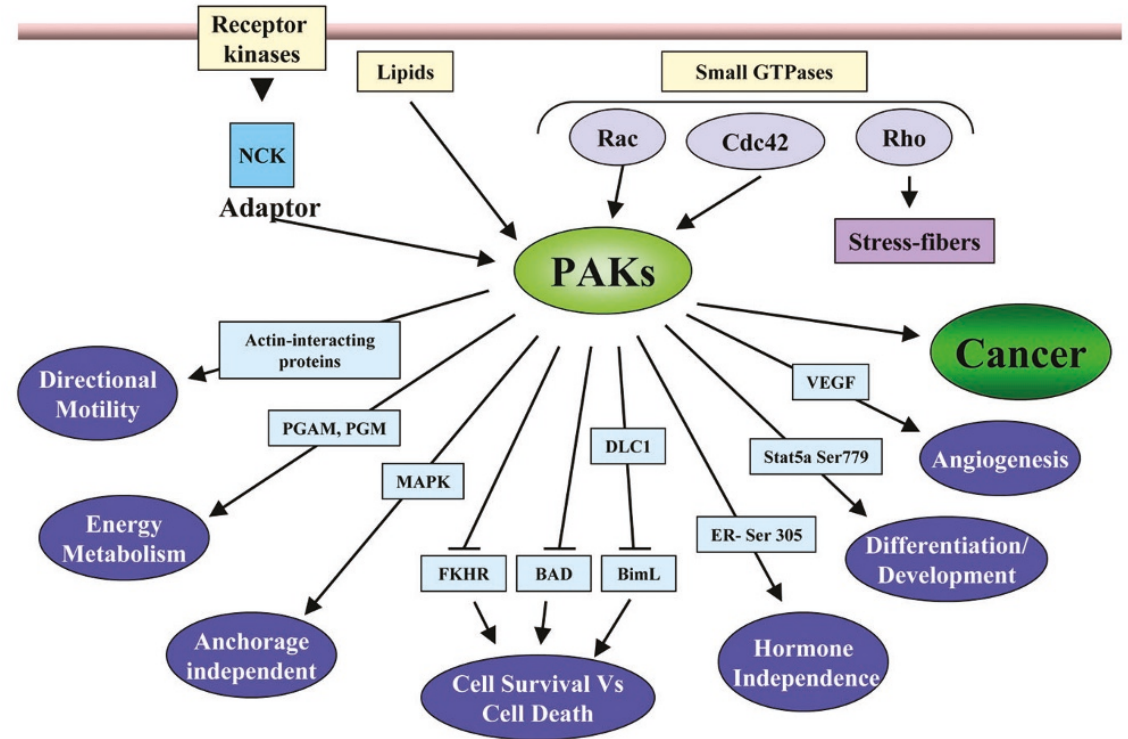

p21-activated kinase (PAK) as a signaling nodule in breast cancer cells. Mechanisms of PAK activation and downstream physiological effects of PAKs are indicated, emphasizing the multiple functions of PAKs in cells. PAKs act upstream of several effectors. The effectors and the outcomes they influence are shown in this schematic. DLC1, dynein light chain 1; ER, estrogen receptor; MAPK, mitogen-activated protein kinase; PGAM, phosphoglyceraldehyde mutase; PGM, phosphoglucomutase; VEGF, vascular endothelial growth factor.

highly conserved throughout evolution in a variety of organisms. Although members of this family share significant homology at the amino acid level, specifically in the kinase domain, the biological function of each member is distinct and is dictated by the variable $\mathrm{N}$-terminal regulatory domain [2].

Although all PAKs interact with GTPases, not all PAKs are activated by such interaction. GTPase induces activity of Pak1-Pak3, whereas binding of GTPases to Pak4-Pak6 does not lead to their activation [5]. Lipids can activate Pak1 either directly or via phosphorylated 3-phosphoinositide-dependent kinase 1 [3]. In addition, PAKs can be phosphorylated on various residues by both serine/ threonine kinases like Akt and Cdk5, and also by tyrosine kinases such as $\mathrm{Ab} 1$ and Etk/Bmx [7,8]. Interestingly, the consensus sequence for Pak1 was deduced based on the sequence similarity of Pak1 to the catalytic domain of myosin 1 heavy chain kinase. Phosphorylation of synthetic substrates containing the consensus phosphorylation site sequence of myosin 1 heavy chain kinase indicated that Pak1 also had the same consensus sequence [9]. Activated PAK proteins phosphorylate a variety of substrates on serine/threonine residues, preferably in the context of basic residues such as $K / R, R / X, X$, and $S / T$, to bring about cell survival and migration, cytoskeleton remodeling, and gene regulation. Table 1 presents a list of known PAK substrates along with the phosphorylation site cytoskeletal dynamics is well documented [4]. In addition to playing a role in cytoskeletal changes, PAKs act as nodal kinases that activate downstream signaling cascades like mitogen-activated protein kinases, JunN Nterminal kinase, and NF- $\mathrm{KB}$ to bring about a plethora of cellular responses $[2,10]$.

\section{PAKs in cancer}

Emerging evidence suggests that PAK family members play an important role in cell survival, motility, angiogenesis, and gene regulation - and thus the PAK family may constitute a critical signaling nodule during tumor progression. Early studies indicated that a dominantnegative PAK mutant inhibits transformation of murine fibroblasts transformed with several oncogenes including Ras, Rac1, Cdc42, or Vav3 [11-13]. Pak1 expression was also increased during malignant progression of human colorectal carcinoma [14]. Recent findings also strongly indicate that Pak1 activation is necessary for lysophosphatidic acid-induced and autotoxin-induced cell motility in melanoma cells [15]. Furthermore, Pak1 activity was found to be higher in tumor tissues as compared with their normal counterparts in head and neck tumors [16]. It has also been demonstrated that transformation by Kaposi's sarcoma-associated herpes virus, which induces Kaposi's sarcoma and primary effusion lymphomas, requires the activation of Pak1 [17]. Results from a large, combined comparative genomic hybridization array and tissue microarray analysis have also identified $P A K 1$ as an 
Table 1

\begin{tabular}{|c|c|c|}
\hline Substrate & $\begin{array}{l}\text { Phosphorylation } \\
\text { sequence }\end{array}$ & Reference \\
\hline LIMK & KRYT & [62] \\
\hline Myosin II light chain & RATS & [63] \\
\hline Myosin II light chain kinase & GRLS, RPKS & {$[64,65]$} \\
\hline Synapsin & RXXS & {$[66]$} \\
\hline Caldesmon & NIKS, GVSS & {$[67,68]$} \\
\hline Op18/stathmin & KRAS & [69] \\
\hline Merlin & KRLS & [20] \\
\hline Filamin A & RAPS & [70] \\
\hline Raf-1 & QRDS & [71] \\
\hline MEK-1 & RPLS & {$[72]$} \\
\hline p47phox & RRNS & [73] \\
\hline Bad & RHSS, RSRS & {$[7,74]$} \\
\hline Estrogen receptor & KKNS & [25] \\
\hline GEF-H1 & RRRS & [11] \\
\hline G $\quad z$ & ARRS & [75] \\
\hline Phosphoglycerate mutase- $B$ & NRFS, WRRS & [76] \\
\hline Prolactin & RRDS & {$[77]$} \\
\hline RhoGDI & KKaS & [78] \\
\hline Desmin & KRAS & [67] \\
\hline Vimentin & SSS, RPSS, LRSS, TTS & [79] \\
\hline Histone 3 & ARKS & [42] \\
\hline C-terminal binding protein 1 & RVaS & [35] \\
\hline Dynein light chain 1 & FKS & [38] \\
\hline P41 ARC & KDRT & [80] \\
\hline Phosphoglucomutase & KVYT & [47] \\
\hline STAT5a & ARLS & [23] \\
\hline
\end{tabular}

overamplified critical oncogene target with a positive correlation with cyclin $D_{1}$ in ovarian carcinomas [18].

In another work, Callow and colleagues [19] analyzed the roles of Pak4 and Pak6 in human tumorigenesis. In a panel of cell lines derived from leukemias, melanomas, breast cancer, colon cancer, lung cancer, liver cancer, ovarian cancer, and renal cancer, Pak4 was found to be overexpressed compared with the expression in normal control tissue in $78 \%$ of samples. The authors found that the Pak4 gene localizes at a region of chromosome 19 that is commonly amplified in a number of human pancreatic tumors, colon tumors, and ovarian tumors [19]. In addition, an activated allele of Pak4 had transforming potential while an inactive Pak4 mutant blocked Rasdependent anchorage independent growth, further strengthening the role of Pak4 in tumorigenesis [19].

The status of PAK, possibly Pak2, could also affect the pathophysiology of the neurofibromatosis type 2 patients. The neurofibromatosis type 2 tumor-suppressor gene product Merlin is mutated in the germline of neurofibromatosis type 2 patients and predisposes affected individuals to intracranial and spinal tumors. In an elegant investigation, Merlin was demonstrated to be phosphorylated by PAK at Ser518, a site that affects Merlin activity and localization [20]. Conversely, Merlin inhibited Pak1 activation and recruitment to focal adhesions. The absence of Merlin resulted in inappropriate activation of Pak1, providing a possible mechanism for effects seen accompanying loss of Merlin expression in tumorigenesis [21]. Pak2 was recently demonstrated to be a negative regulator of myc protein, suggesting that Pak2 could potentially be used for therapy to inhibit myc-induced neoplasia [22].

\section{Mouse mammary gland PAK models}

Pak1 expression is activated in mammary glands in a development-dependent manner, with the highest activity during pregnancy and lactation [23]. Clues about the role of Pak1 in the mammary gland came from a recent transgenic model expressing a kinase dead Pak1 mutant. Inactivation of Pak1 led to incomplete lobulo-alveolar development and impaired functional differentiation (Fig. 2a). Interestingly, Pak1 directly interacted with and phosphorylated Stat5a at Ser779, which was substantially reduced in transgenic mammary glands, suggesting a role for Pak1 during alveolar morphogenesis and differentiation [23]. Pak1 expression and activation has also been linked with epithelial differentiation during rodent development [24]. In contrast, persistent activation of Pak1 in mammary epithelium was accompanied by widespread hyperplasia, lobulo-alveolar hyperdevelopment during lactation, and stimulation of the estrogen receptor (ER) target genes [25]. In addition to Pak1, overexpression of the Rac3 transgene, an upstream activator of Pak1, in mammary epithelium impaired the normal physiology and led to the formation of mammary gland lesions [26].

\section{PAK signaling in breast cancer}

Since Pak1 was originally thought to be involved in directional cell motility, and because cell motility is important for productive metastasis, we initially set out to search for the role of Pak1 in breast cancer, and discovered a definitive role of Pak1 in HER2-mediated increased invasiveness [10]. Subsequent studies suggested a positive correlation between the expression and activity of Pak1 and the invasiveness of human breast cancer cells and breast tumor grades (Fig. 2b) [27,28]. The expression of Pak1 in human breast tumor tissue 


\section{Figure 2}

(a)

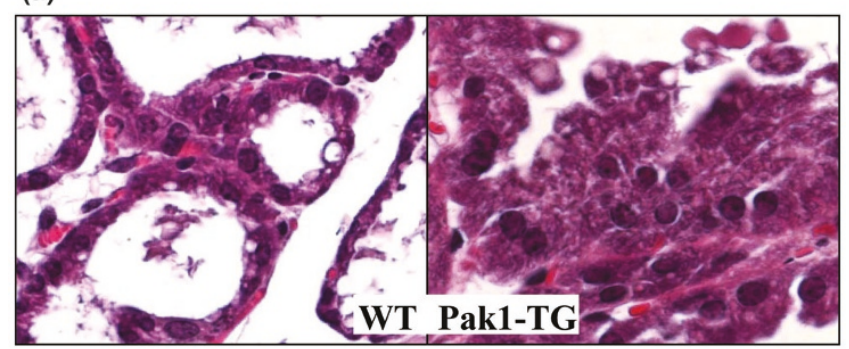

(b)

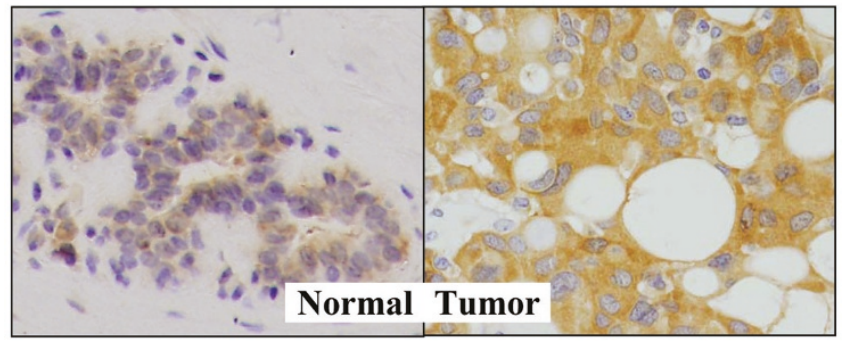

Known phenotypic changes in mammary epithelium and breast cancer. (a) Overactivation of p21-activated kinase Pak1 in mouse mammary gland induced hyperplasia. While the wild-type (WT) mouse mammary gland has only one single layer of cells (left panel), the mammary gland of the Pak1-TG mice reveals many layers of cells protruding into the lumen of alveoli (right panel). (b) Immunohistochemical detection of Pak1 in normal and breast tumor sections. Left panel, normal section showing weak cytoplasmic Pak1 expression; right panel, tumor section showing an intense cytoplasmic staining compared with the normal section.

correlates with the tumor grade, with higher expression in less differentiated ductal carcinomas of the breast (grade III tumors) than in grade II and grade I tumors [29]. Since Pak1 is downstream of phosphatidylinositol 3 (PI-3) kinase and $\mathrm{Pl}-3$ kinase is negatively regulated by phosphatase and tensin homolog, some of the high Pak1 activity might result from phosphatase and tensin homolog inactivation, as has been shown in 11 resected breast tumors with phosphatase and tensin homolog mutations [29]. Inhibition of Pak1 using kinase-dead Pak1-K299R in highly invasive MDA-MB435 breast cancer cells was associated with excessive cell spreading and accumulation of mature focal points [30]. A recent study showed that constitutively activated endogenous PAK is mislocalized to atypical focal adhesions in the absence of high levels of activated Rho GTPases [28]. These studies emphasize the involvement of PAKs in breast cancer genesis and metastasis.

\section{PAK, a major nodule of growth factor signaling}

Aberrant growth factor signaling is one of the hallmarks of cancer. The acquisition of an invasive phenotype by

human breast cancer cells has also been attributed to the stimulation by growth factor signaling. Human epidermal growth factor receptor (HER) 2 and HER3 expression and activity have been shown to correlate with breast cancer progression and prognosis [31]. In breast cancer cells, Pak1 activity increased in response to heregulin in a $\mathrm{PI}-3$ kinase-dependent manner. Inhibition of HER2 using herceptin resulted in the blockade of both $\mathrm{Pl}-3$ kinase/PAK activation and the formation of actin structures, further confirming the involvement of Pak1 in cytoskeletal rearrangements [10].

Highly proliferative human breast cancer-derived cell lines and tumor tissues have also been shown to contain hyperactive Rac3 and hyperactive Pak1 and Pak2 [32]. Validation experiments with dominant-negative PAK mutants revealed the critical significance of the Rac3-PAK pathway for DNA synthesis and tumor growth [32]. The PI-3 kinase/Pak1/p38 mitogen-activated protein kinase (MAPK) pathway has also been shown to be hyperactivated in breast tumors, and Pl-3 kinase and Pak1 are co-overexpressed in breast tumors [29].

In addition to Pak1 activation by deregulated growth factors, PAK signaling could also be stimulated by its upstream activators. For example, high Rac1b expression has been reported in ductal carcinoma in situ, in primary breast cancer, and in lymph node metastases, as compared with benign breast disease. Since many of these patients with recurrent disease exhibited intense Rac1b expression at the plasma membrane, it is possible that Rac1b, and hence its effector PAK, might be constitutively activated in patients with aggressive breast cancer [33]. Similarly, PAK interacting exchange factor (betaPix), an activator of Cdc42/Rac and PAK kinase activity, was also found to increase membrane ruffling and to upregulate in human breast cancer tissues [34].

Recent studies also demonstrate that Pak1 phosphorylates and blocks the corepressor functions of the $\mathrm{C}$ terminal binding protein 1 in growth-factor-activated breast cancer cells [35]. C-terminal binding protein 1 links the recruitment of DNA-modifying and histone-modifying proteins to sequence-specific DNA-binding proteins, and facilitates gene regulation during development and oncogenesis. C-terminal binding protein 1 phosphorylation and inactivation by Pak1 may induce putative genes by derepression [35]. It may thus be concluded that aberrant mitogenic signaling in human breast cancers involve both upstream modulators and downstream effectors of PAKs.

\section{PAK regulation of cancerous phenotypes}

The expression of a catalytically active Pak1 mutant stimulates anchorage-independent growth of breast cancer cells in soft agar through a preferential MAPKsensitive manner [30]. Interestingly, inhibition of protein 
kinase A (PKA) also promotes anchorage-independent stimulation of the MAPK cascade by growth factors via PAK [36]. However, PKA has also been shown to positively regulate Rac1 in growth-factor-activated cells [37]. It is clear that Pak1-associated cancerous phenotypes could result from the functional dysregulation of specific PAK substrates. For example, recent data showed that dynein light chain 1 (DLC1), a component of the dynein motor, is a physiological Pak1-interacting substrate, and that Pak1 phosphorylation of DLC1 at Ser88 plays a critical role in supporting the growth of breast cancer cells in an anchorage-independent manner and in nude mice [38]. Furthermore, DLC1 was dysregulated in breast cancer samples, and approximately one-half of the tumors had increased expression of both Pak1 and DLC1 [38].

\section{PAK and the cell cycle}

In lower eukaryotes, Pak1 homologs were demonstrated to be important in cell cycle events including mitosis, cytokinesis, and microtubule stabilization [39]. Initial clues about the role of Pak1 in mammalian cell division came from studies defining regulated phosphorylation of Pak1 in fibroblasts and neuronal cells $[40,41]$. In these studies, phosphorylation of Pak1 was implicated in cell-cycle regulation and was shown to affect microtubules in cells undergoing mitosis. Further support for a definitive role for Pak1 in the development of chromosomal abnormalities came from studies where breast cancer cells overexpressing activated Pak1 exhibited abnormal organization of mitotic spindles [30].

An unexpected function for Pak1 in mitotic cells was revealed when Histone $\mathrm{H} 3$ was identified as a Pak1 substrate [42]. Pak1 phosphorylates Histone H3.3 on Ser10, a post-translational modification of Histone $\mathrm{H} 3$ that has been linked with regulation of mitotic chromosomal assembly, with congregation at the metaphase plate, and with segregation [42]. The results of this study have fascinating implications with respect to the role played by Pak1 in its activated state (as observed in most cancer cells) on cellular events responsible for incorrect DNA ploidy of tumor cells. Another study suggested that cyclin $\mathrm{B}_{1} / \mathrm{Cdc} 2$ phosphorylates Pak1 in cells undergoing mitosis [41]. It could thus be speculated that abnormal segregation of chromosomes during mitosis in tumor cells results, at least in part, from persistent activation of Pak1 in these cells.

\section{Anti-apoptotic action of PAKs and its effectors}

PAKs promote cell proliferation and survival, presumably by phosphorylating and inhibiting the pro-apoptotic protein Bad, caspase-3, caspase-8, and FKHR [43-45]. Phosphorylated Bad demonstrates reduced interaction with $\mathrm{Bcl}-2$ and $\mathrm{Bcl}-\mathrm{xL}$, and demonstrates increased interaction with 14-3-3 tau. Pak1 activation, and resulting inactivation of Bad, is also sufficient to antagonize p38 MAPK as well as its upstream activator MKK6-induced cell death [46]. In addition, Pak1 utilizes its newly identified substrate, the DLC1, to confer enhanced cell survival in breast cancer cells, through a mechanism dependent on Pak1's phosphorylation of DLC1 on Ser88. Of specific interest is the Pak1-regulated interaction of DLC1 with BimL, a BH3-only domain pro-apoptotic protein. It was shown that Pak1 antiapoptotic function derive, in part, from its recognition of DLC1-BimL dimers, which are released upon apoptotic signals from the dynein motors. Pak1 phosphorylation of both DLC1 and BimL prevents the ability of BimL to interact and inactivate Bcl-2 [38]. Since cell survival function is dependent on efficient energy utilization, PAK signaling has now been linked with components of the glycolytic pathway, phosphoglyceraldehyde mutase (reviewed in [2]) and phosphoglucomutase [47].

\section{PAK in angiogenesis}

Angiogenesis, the growth of new blood vessels from existing blood vessels, is heavily implicated in tumor growth and metastasis. Vascular endothelial growth factor (VEGF) is one of the major players in the process of angiogenesis. Pak1 signaling is required for VEGF expression and, consequently, for VEGF function [48]. In addition, VEGF also signals via Pak1 to bring about its downstream effects [49]. Specific involvement of Pak1 was confirmed by inhibition of endothelial cell migration by both dominant-negative Pak1 and an N-terminal prolinerich Pak1 peptide [50]. Furthermore, heregulin was shown to upregulate the synthesis of hypoxia-inducible factor 1 alpha, a director activator of VEGF [51]. Since HER2 as well as Pak1 are known to induce VEGF expression, and because HER2 signaling stimulates Pak1 activity [10], these findings suggest that HER2 activation by growth factors stimulates VEGF expression, presumably via hypoxia-inducible factor 1 alpha. Recent studies also indicate that the Rac/PAK pathway is essential for ephrin $\mathrm{A}_{1}$-mediated inhibition of cell spreading that participates in blood vessel destabilization, a prerequisite for angiogenesis [52]. These results further suggest a role for Pak1 in angiogenesis. In contrast, microtubule depolymerization by agents like vinblastine induced cleavage of Pak2 along with procaspases, leading to the collapse of the capillary tube network and endothelial cell apoptosis [53]. This is an example of distinct functions exhibited by different members of the PAK family in the cell.

\section{PAK in ER signaling}

Human breast cancers and the cell models derived from them can be classified into those that are steroid hormone dependent and those that grow independent of estradiol. An effect of Pak1, which is important for hormonedependent breast cancer, is its ability to phosphorylate the 
Figure 3

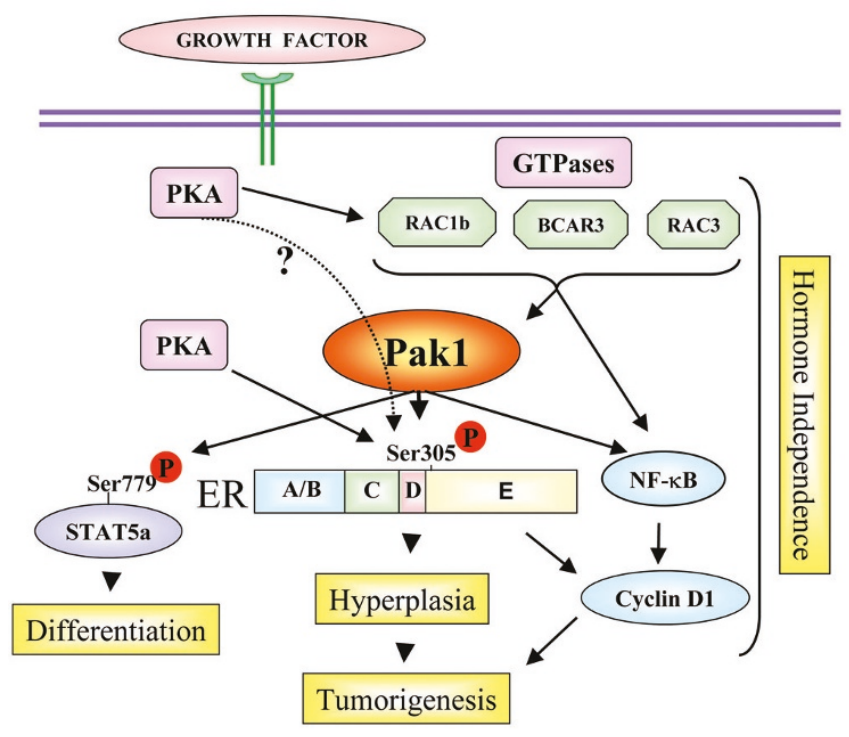

A schematic model of p21-activated kinase (PAK) action in the absence of estrogen in breast cancer cells. A simplified summary of the cellular events in which regulation of cancer-related events by PAKs has been implicated. Both the $\mathrm{N}$-termini and $\mathrm{C}$-termini of PAK can interact with various signaling components and thus promote specific changes required for cells to acquire a cancerous and metastatic phenotype. Broken lines, proposed regulation. ER, estrogen receptor; PKA, protein kinase $A$.

ER either directly or indirectly. Wang and colleagues demonstrated that Pak1 phosphorylates the ER at Ser305 and promotes its transactivation (Fig. 3) [25]. Furthermore, transgenic mice that express kinase-active Pak1 develop hyperplasia in the mammary epithelium and have increased expression of ER target genes [23]. In highly metastatic ER-positive breast carcinomas, the locus to which PAK has been mapped, 11q13, is amplified [54]. Steroid hormone-independent subtypes often utilize pathways involving peptide hormones or growth factor. Since Pak1 could be activated by growth factor signaling, these findings imply that Pak1 might regulate the ER pathway in ligand-independent phenotypes.

The consensus phosphorylation motif in the PAK substrates is not very restricted and is common with other kinases such as ribosomal S6 kinase [55] and PKA [36]. Consistent with this hypothesis, a recent report showed that PKA phosphorylation of the ER at Ser305 induces resistance to tamoxifen [56]. Since the downstream effects of PKA could be blocked by dominant-negative Rac1 [37], and because Rac1 is a direct activator of Pak1, it is tempting to speculate that Pak1 could be downstream of PKA in affecting the function of the ER. Current studies are testing this model (S Rayala, R Kumar, cascades involved, it is increasingly clear that ER phosphorylation at Ser305 represents an important modification for ligand independence and/or tamoxifen resistance in breast cancer cells.

ER activation by Pak1 also induces upregulation of cyclin $D_{1}$ in breast cancer cells, as well as in the mammary epithelium [57]. In addition, Pak1 could also upregulate cyclin $\mathrm{D}_{1}$ expression in an ER-independent, but NF-кBdependent, manner [57]. In addition, Pak1 has also been implicated in the induction of cyclin $D_{1}$ as well as in the development of resistance to AND34/BCAR3, an upstream activator of Pak1 [58]. These findings suggest that Pak 1 could potentially regulate cyclin $D_{1}$ expression in both ER-positive and ER-negative breast cancer cells (Fig. 3). Another of the PAK family members known to interact with nuclear receptors is Pak6, which interacts with ER; 4-hydroxytamoxifen enhances their interaction [59]. The ability of PAK members to interact with steroid hormonal receptors suggests that PAKs may play an important role in the cross-talk between steroid hormone receptors and growth factor signaling pathways.

\section{Therapeutic implication of PAK research}

Since PAK signaling is important in the process of tumorigenesis, any interference with PAK and/or one of its critical downstream substrates may be a useful therapeutic approach. Use of dominant-negative expression plasmids of Pak1 controls the metastasis of a number of types of tumor cells $[10,39]$. Because Pak1 is a pro-survival signal in cells, interfering with its activity and signaling should induce apoptosis in tumors, leading to tumor regression. Nheu and colleagues [60] have recently developed a first generation of compounds that target the activity of PAKs. Two synthetic derivatives of an adenosine triphosphate antagonist, CEP-1347 and KT D606, target PAKs and inhibit the growth of transformed murine fibroblasts. The recent elucidation of the Pak1 crystal structure [61] should aid the development of specific Pak1 inhibitors. A recent study identified a small peptide that can interfere with Nck binding to Pak1, which can interfere with angiogenesis [48], suggesting that small molecule interference of PAK interaction with its binding proteins may have some therapeutic value.

Since Pak1 represents a common convergence nodule of receptor tyrosine kinases, PI-3 kinase-AKT, Ras, small GTPases, and lipid signaling, the impact of Pak1 signaling on the biology of cancer cells is not limited to breast cancer (with the exception of ER regulation). Hence, lessons from breast cancer model systems are applicable to other cancer types and should aid in the development of targeted anticancer therapies.

\section{Competing interests}

The author(s) declare that they have no competing interests. 


\section{Acknowledgements}

The work in the Kumar laboratory is supported by National Institute of Health grant CA90970 and grant CA80066 (to RK). The authors thank the members of the laboratory for useful discussions. The authors apologize to several of their colleagues for not citing their primary references owing to space limitation.

\section{References}

1. Etienne-Manneville S, Hall A: Rho GTPases in cell biology. Nature 2002, 420:629-635.

2. Bokoch GM: Biology of the p21-activated kinases. Annu Rev Biochem 2003, 72:743-781.

3. Bokoch GM: Regulation of cell function by Rho family GTPases. Immunol Res 2000, 21:139-148.

4. Kumar R, Vadlamudi RK: Emerging functions of p21-activated kinases in human cancer cells. J Cell Physiol 2002, 193:133144.

5. Jaffer ZM, Chernoff J: p21-activated kinases: three more join the Pak. Int J Biochem Cell Biol 2002, 34:713-717.

6. Manser E, Leung T, Salihuddin H, Zhao ZS, Lim L: A brain serine/threonine protein kinase activated by $\mathrm{Cdc} 42$ and Rac1. Nature 1994, 367:40-46.

7. Tang $Y$, Zhou H, Chen A, Pittman RN, Field J: The Akt protooncogene links Ras to Pak and cell survival signals. J Biol Chem 2000, 275:9106-9109.

8. Bagheri $\mathrm{Y}$, Mandal M, Taludker $\mathrm{AH}$, Wang RA, Vadlamudi RK, Kung HJ, Kumar R: Etk/Bmx tyrosine kinase activates Pak1 and regulates tumorigenicity of breast cancer cells. J Biol Chem 2001, 276:29403-29409.

9. Brzeska H, Knaus UG, Wang ZY, Bokoch GM, Korn ED: p21activated kinase has substrate specificity similar to Acanthamoeba myosin I heavy chain kinase and activates Acanthamoeba myosin I. Proc Natl Acad Sci USA 1997, 94: 1092-1095.

10. Adam L, Vadlamudi R, Kondapaka SB, Chernoff J, Mendelsohn J, Kumar R: Heregulin regulates cytoskeletal reorganization and cell migration through the p21-activated kinase-1 via phosphatidylinositol-3 kinase. I Biol Chem 1998, 273:2823828246.

11. Tang Y, Chen Z, Ambrose D, Liu J, Gibbs JB, Chernoff J, Field J: Kinase-defective Pak1 mutants inhibit ras transformation of Rat-1 fibroblasts. Mol Cell Biol 1997, 17:4454-4464.

12. Tang $Y, Y u J$, Field J: Signals from the Ras, Rac, and Rho GTPases converge on the Pak protein kinase in Rat-1 fibroblasts. Mol Cell Biol 1999, 19:1881-1891.

13. He H, Hirokawa $Y$, Manser E, Lim L, Levitzki A, Maruta H: Signal therapy for RAS-induced cancers in combination of AG $\mathbf{8 7 9}$ and PP1, specific inhibitors for ErbB2 and Src family kinases, that block PAK activation. Cancer J 2001, 7:191-202.

14. Carter JH, Douglass LE, Deddens JA, Colligan BM, Bhatt TR, Pemberton JO, Konicek S, Hom J, Marshall M, Graff JR: Pak-1 expression increases with progression of colorectal carcinomas to metastasis. Clin Cancer Res 2004, 10:3448-3456.

15. Jung ID, Lee J, Lee KB, Park CG, Kim YK, Seo DW, Park D, Lee HW, Han JW, Lee HY: Activation of p21-activated kinas 1 is required for lysophosphatidic acid-induced focal adhesion kinas phosphorylation and cell motility in human melanoma A2058 cells. Eur J Biochem 2004, 271:1557-1565.

16. Yang $Z$, Bagheri-Yarmand $R$, Wang RA, Adam L, Papadimitrakopoulou VV, Clayman GL, El-Naggar A, Lotan R, Barnes CJ, Hong WK, Kumar R: The epidermal growth factor receptor tyrosine kinase inhibitor ZD1839 (Iressa) suppresses c-Src and Pak1 pathways and invasiveness of human cancer cells. Clin Cancer Res 2004, 10:658-667.

17. Dadke D, Fryer BH, Golemis EA, Field J: Activation of p21-activated kinase 1-nuclear factor kappaB signaling by Kaposi's sarcoma-associated herpes virus $\mathrm{G}$ protein-coupled receptor during cellular transformation. Cancer Res 2003, 63:88378847.

18. Schraml P, Schwerdtfeger G, Burkhalter F, Raggi A, Schmidt D, Ruffalo T, King W, Wilber K, Mihatsch MJ, Moch H: Combined array comparative genomic hybridization and tissue microarray analysis suggest PAK1 at 11q13.5-q14 as a critical oncogene target in ovarian carcinoma. Am J Pathol 2003, 163:985-992.
19. Callow MG, Clairvoyant F, Zhu S, Schryver B, Whyte DB, Bischoff JR, Jallal B, Smeal T: Requirement for PAK4 in the anchorageindependent growth of human cancer cell lines. J Biol Chem 2002, 277:550-558.

20. Xiao GH, Beeser A, Chernoff J, Testa JR: p21-activated kinase links Rac/Cdc42 signaling to merlin. J Biol Chem 2002, 277: 883-886.

21. Kissil JL, Wilker EW, Johnson KC, Eckman MS, Yaffe MB, Jacks $\mathrm{T}$ : Merlin, the product of the Nf2 tumor suppressor gene, is an inhibitor of the p21-activated kinase, Pak1. Mol Cell 2003, 12: 841-849.

22. Huang Z, Traugh JA, Bishop JM. Negative control of the Myc protein by the stress-responsive kinase Pak2. Mol Cell Biol 2004, 24:1582-1594.

23. Wang RA, Vadlamudi RK, Bagheri-Yarmand R, Beuvink I, Hynes NE, Kumar R: Essential functions of p21-activated kinase 1 in morphogenesis and differentiation of mammary glands. J Cell Biol 2003, 161:583-592.

24. Zhong JL, Banerjee MD, Nikolic M: Pak1 and its T212 phosphorylated form accumulate in neurones and epithelial cells of the developing rodent. Dev Dyn 2003, 228:121-127.

25. Wang RA, Mazumdar A, Vadlamudi RK, Kumar R: P21-activated kinase- 1 phosphorylates and transactivates estrogen receptor-alpha and promotes hyperplasia in mammary epithelium. EMBO J 2002, 21:5437-5447.

26. Leung K, Nagy A, Gonzalez-Gomez I, Groffen J, Heisterkamp N, Kaartinen $V$ : Targeted expression of activated Rac3 in mammary epithelium leads to defective postlactational involution and benign mammary gland lesions. Cells Tissues Organs 2003, 175:72-83.

27. Balasenthil S, Sahin AA, Barnes CJ, Wang RA, Pestell RG, Vadlamudi RK, Kumar R: p21-activated kinase-1 signaling mediates cyclin D1 expression in mammary epithelial and cancer cells. $J$ Biol Chem 2004, 279:1422-1428.

28. Stofega MR, Sanders LC, Gardiner EM, Bokoch GM: Constitutive p21-activated kinase (PAK) activation in breast cancer cells as a result of mislocalization of PAK to focal adhesions. Mol Biol Cell 2004, 15:2965-2977.

29. Salh B, Marotta A, Wagey R, Sayed M, Pelech S: Dysregulation of phosphatidylinositol 3-kinase and downstream effectors in human breast cancer. Int J Cancer 2002, 98:148-154.

30. Vadlamudi RK, Adam L, Wang RA, Mandal M, Nguyen D, Sahin A, Chernoff J, Kumar R: Regulatable expression of p21-activated kinase-1 promotes anchorage-independent growth and abnormal organization of mitotic spindles in human epithelial breast cancer cells. J Biol Chem 2000, 275:36238-36244.

31. Carlsson J, Nordgren H, Sjostrom J, Wester K, Villman K, Bengtsson NO, Ostenstad B, Lundqvist H, Blomqvist C: HER2 expression in breast cancer primary tumours and corresponding metastases. Original data and literature review. $\mathrm{Br} J$ Cancer 2004, 90:2344-2348.

32. Mira JP, Benard V, Groffen J, Sanders LC, Knaus UG: Endogenous, hyperactive Rac3 controls proliferation of breast cancer cells by a p21-activated kinase-dependent pathway. Proc Nat/ Acad Sci USA 2000, 97:185-189.

33. Schnelzer A, Prechtel D, Knaus U, Dehne K, Gerhard M, Graeff H, Harbeck N, Schmitt M, Lengyel E: Rac1 in human breast cancer: overexpression, mutation analysis, and characterization of a new isoform, Rac1b. Oncogene 2000, 19:3013-3020.

34. Ahn SJ, Chung KW, Lee RA, Park IA, Lee SH, Park DE, Noh DY: Overexpression of betaPix-a in human breast cancer tissues. Cancer Lett 2003, 193:99-107.

35. Barnes CJ, Vadlamudi RK, Mishra SK, Jacobson RH, Li F, Kumar $\mathrm{R}$ : Functional inactivation of a transcriptional corepressor by a signaling kinase. Nat Struct Biol 2003, 10:622-628.

36. Howe AK, Juliano RL: Regulation of anchorage-dependent signal transduction by protein kinase $A$ and p21-activated kinase. Nat Cell Biol 2000, 2:593-600.

37. O'Connor KL, Mercurio AM: Protein kinase A regulates Rac and is required for the growth factor-stimulated migration of carcinoma cells. J Biol Chem 2001, 276:47895-47900.

38. Vadlamudi RK, Bagheri-Yarmand R, Yang Z, Balasenthil S, Nguyen D, Sahin AA, den Hollander P, Kumar R: Dynein light chain 1, a p21-activated kinase 1-interacting substrate, promotes cancerous phenotypes. Cancer Cell 2004, 5:575-585.

39. Faure S, Vigneron S, Galas S, Brassac T, Delsert C, Morin N: Control of G2/M transition in Xenopus by a member of the 
p21-activated kinase (PAK) family: a link between protein kinase A and PAK signaling pathways? J Biol Chem 1999, 274:3573-3579.

40. Thiel D, Reeder M, Pfaff A, Coleman T, Sells M, Chernoff J: Cell cycle-regulated phosphorylation of p21-activated kinase 1. Curr Biol 2002, 12:1227-1232.

41. Banerjee M, Worth D, Prowse D, Nikolic M: Pak1 phosphorylation on t212 affects microtubules in cells undergoing mitosis. Curr Biol 2002, 12:1233-1239.

42. Li F, Adam L, Vadlamudi RK, Zhou H, Sen S, Chernoff J, Mandal M, Kumar R: p21-activated kinase 1 interacts with and phosphorylates histone $\mathrm{H} 3$ in breast cancer cells. EMBO Rep 2002, 3:767-773.

43. Schurmann A, Mooney AF, Sanders LC, Sells MA, Wang HG, Reed JC, Bokoch GM: p21-activated kinase 1 phosphorylates the death agonist bad and protects cells from apoptosis. Mol Cell Biol 2000, 20:453-461.

44. Gnesutta N, Minden A: Death receptor-induced activation of initiator caspase 8 is antagonized by serine/threonine kinase PAK4. Mol Cell Biol 2003, 23:7838-7848.

45. Mazumdar A, Kumar R: Estrogen regulation of Pak1 and FKHR pathways in breast cancer cells. FEBS Lett 2003, 535:6-10.

46. Deacon K, Mistry P, Chernoff J, Blank JL, Patel R: p38 Mitogenactivated protein kinase mediates cell death and p21-activated kinase mediates cell survival during chemotherapeutic druginduced mitotic arrest. Mol Biol Cell 2003, 14:2071-2087.

47. Gururaj A, Barnes CJ, Vadlamudi RK, Kumar R: Phosphoglucomutase 1 regulation by $\mathbf{2 1}$-activated kinase 1 . Oncogene 2004, 23:8118-8127.

48. Bagheri-Yarmand R, Vadlamudi RK, Wang R, Mendelsohn J, Kumar R: Vascular endothelial growth factor upregulation via p21-activated kinase-1 signaling regulates heregulin-b1mediated angiogenesis. J Biol Chem 2000, 275:39451-39457.

49. Chau CH, Chen KY, Deng HT, Kim KJ, Hosoya K, Terasaki T, Shih $\mathrm{HM}$, Ann DK: Coordinating Etk/Bmx activation and VEGF upregulation to promote cell survival and proliferation. Oncogene 2002, 21:8817-8829.

50. Kiosses WB, Hood J, Yang S, Gerritsen ME, Cheresh DA, Alderson N, Schwartz MA: A dominant-negative p65 PAK peptide inhibits angiogenesis. Circ Res 2002, 90:697-702.

51. Laughner E, Taghavi $P$, Chiles K, Mahon PC, Semenza GL: HER2 (neu) signaling increases the rate of hypoxia-inducible factor 1alpha (HIF-1alpha) synthesis: novel mechanism for HIF-1mediated vascular endothelial growth factor expression. Mol Cell Biol 2001, 21:3995-4004.

52. Deroanne C, Vouret-Craviari V, Wang B, Pouyssegur J: EphrinA1 inactivates integrin-mediated vascular smooth muscle cell spreading via the Rac/PAK pathway. J Cell Sci 2003, 116: 1367-1376.

53. Bayless KJ, Davis GE: Microtubule depolymerization rapidly collapses capillary tube networks in vitro and angiogenic vessels in vivo through the small GTPase Rho. J Biol Chem 2004, 279:11686-11695.

54. Bekri S, Adelaide J, Merscher S, Grosgeorge J, Caroli B, Perucca L, Kelley PM, Pebusque MJ, Theillet C, Birnbaum D, Gaudray P: Detailed map of a region commonly amplified at 11q13?q14 in human breast carcinoma. Cytogenet Cell Genet 1997, 79: 125-131.

55. Woo MS, Ohta Y, Rabinovitz I, Stossel TP, Blenis J: Ribosomal S6 kinase (RSK) regulates phosphorylation of filamin A on an important regulatory site. $\mathrm{Mol}$ Cell Biol 2004, 24:3025-3035.

56. Michalides R, Griekspoor A, Balkenende A, Verwoerd D, Janssen L, Jalink K, Floore A, Velds A, van't Veer L, Neefjes J: Tamoxifen resistance by a conformational arrest of the estrogen receptor alpha after PKA activation in breast cancer. Cancer Cell 2004, 5:597-605.

57. Balasenthil S, Barnes CJ, Rayala SK, Kumar R: Estrogen receptor activation at serine 305 is sufficient to upregulate cyclin D1 in breast cancer cells. FEBS Lett 2004, 567:243-247.

58. Cai D, lyer A, Felekkis KN, Near RI, Luo Z, Chernoff J, Albanese C, Pestell RG, Lerner A: AND-34/BCAR3, a GDP exchange factor whose overexpression confers antiestrogen resistance, activates Rac, PAK1, and the cyclin $D_{1}$ promoter. Cancer Res 2003, 63:6802-6808.

59. Lee SR, Ramos SM, Ko A, Masiello D, Swanson KD, Lu ML, Balk SP: AR and ER interaction with a p21-activated kinase (PAK6). Mol Endocrinol 2002, 16:85-99.
60. Nheu TV, He H, Hirokawa Y, Tamaki K, Florin L, Schmitz ML, Suzuki-Takahashi I, Jorissen RN, Burgess AW, Nishimura S, et al.: The K252a derivatives, inhibitors for the PAK/MLK kinase family selectively block the growth of RAS transformants. Cancer J 2002, 8:328-336.

61. Lei M, Lu W, Meng W, Parrini MC, Eck MJ, Mayer BJ, Harrison SC: Structure of PAK1 in an autoinhibited conformation reveals a multistage activation switch. Cell 2000, 102:387397.

62. Edwards DC, Sanders LC, Bokoch GM, Gill GN: Activation of LIM-kinase by Pak1 couples Rac/Cdc42 GTPase signalling to actin cytoskeletal dynamics. Nat Cell Biol 1999, 1:253-259.

63. Ramos E, Wysolmerski RB, Masaracchia RA: Myosin phosphorylation by human cdc42-dependent S6/H4 kinase/gammaPAK from placenta and lymphoid cells. Recept Signal Transduct 1997, 7:99-110.

64. Goeckeler ZM, Masaracchia RA, Zeng Q, Chew TL, Gallagher P, Wysolmerski RB: Phosphorylation of myosin light chain kinase by p21-activated kinase PAK2. J Biol Chem 2000, 275:1836618374.

65. Sanders LC, Matsumura F, Bokoch GM, de Lanerolle P: Inhibition of myosin light chain kinase by p21-activated kinase. Science 1999, 283:2083-2085.

66. Tu Y, Nayak SK, Woodson J, Ross EM: Phosphorylation-regulated inhibition of the Gz GTPase-activating protein activity of RGS proteins by synapsin I. J Biol Chem 2003, 278:5227352281.

67. Van Eyk JE, Arrell DK, Foster DB, Strauss JD, Heinonen TY, Furmaniak-Kazmierczak E, Cote GP, Mak AS: Different molecular mechanisms for Rho family GTPase-dependent, $\mathrm{C}^{\mathrm{a} 2+}$-independent contraction of smooth muscle. J Biol Chem 1998 273:23433-23439.

68. Foster DB, Shen LH, Kelly J, Thibault P, Van Eyk JE, Mak AS: Phosphorylation of caldesmon by p21-activated kinase. Implications for the $\mathrm{Ca}(2+)$ sensitivity of smooth muscle contraction. J Biol Chem 2000, 275:1959-1965.

69. Daub H, Gevaert K, Vandekerckhove J, Sobel A, Hall A: Rac/Cdc42 and p65PAK regulate the microtubule-destabilizing protein stathmin through phosphorylation at serine 16. J Biol Chem 2001, 276:1677-1680.

70. Vadlamudi RK, Li F, Adam L, Nguyen D, Ohta Y, Stossel TP, Kumar R: Filamin is essential in actin cytoskeletal assembly mediated by p21-activated kinase 1. Nat Cell Biol 2002, 4: 681-690.

71. King AJ, Sun H, Diaz B, Barnard D, Miao W, Bagrodia S, Marshall MS: The protein kinase Pak3 positively regulates Raf- 1 activity through phosphorylation of serine 338. Nature 1998, 396: 180-183.

72. Frost JA, Steen $H$, Shapiro $P$, Lewis $T$, Ahn N, Shaw PE, Cobb $\mathrm{MH}$ : Cross-cascade activation of ERKs and ternary complex factors by Rho family proteins. EMBO J. 1997, 16:6426-6438.

73. Knaus UG, Morris S, Dong HJ, Chernoff J, Bokoch GM: Regulation of human leukocyte p21-activated kinases through G protein-coupled receptors. Science 1995, 269:221-223.

74. Schurmann A, Mooney AF, Sanders LC, Sells MA, Wang HG, Reed JC, Bokoch GM: p21-activated kinase 1 phosphorylates the death agonist bad and protects cells from apoptosis. Mol Cell Biol 2000, 20:453-461.

75. Wang J, Frost JA, Cobb MH, Ross EM: Reciprocal signaling between heterotrimeric $G$ proteins and the p21-stimulated protein kinase. J Biol Chem 1999, 274:31641-31647.

76. Shalom-Barak T, Knaus UG: A p21-activated kinase-controlled metabolic switch up-regulates phagocyte NADPH oxidase. $J$ Biol Chem 2002, 277:40659-40665.

77. Tuazon PT, Lorenson MY, Walker AM, Traugh JA: p21-activated protein kinase gamma-PAK in pituitary secretory granules phosphorylates prolactin. FEBS Lett 2002, 515:84-88.

78. DerMardirossian C, Schnelzer A, Bokoch GM: Phosphorylation of RhoGDI by Pak1 mediates dissociation of Rac GTPase. Mol Cell 2004, 15:117-127.

79. Goto H, Tanabe K, Manser E, Lim L, Yasui Y, Inagaki M: Phosphorylation and reorganization of vimentin by p21-activated kinase (PAK). Genes Cells 2002, 7:91-97.

80. Vadlamudi RK, Li F, Barnes CJ, Bagheri-Yarmand R, Kumar R: p41-Arc subunit of human Arp2/3 complex is a p21-activated kinase-1-interacting substrate. EMBO Rep 2004, 5:154-160. 